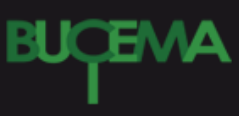

Bulletin du centre d'études médiévales

d'Auxerre | BUCEMA

Hors-série $n^{\circ} 2 \mid 2008$

Le Moyen Âge vu d'ailleurs

\title{
Representar, instituir, redimir : oralidad y escritura en los textos forales
}

\section{Paola Miceli}

\section{(2) OpenEdition \\ 12 Journals}

\section{Edición electrónica}

URL: https://journals.openedition.org/cem/9642

DOI: $10.4000 /$ cem. 9642

ISSN: 1954-3093

\section{Editor}

Centre d'études médiévales Saint-Germain d'Auxerre

\section{Referencia electrónica}

Paola Miceli, «Representar, instituir, redimir : oralidad y escritura en los textos forales », Bulletin du centre d'études médiévales d'Auxerre | BUCEMA [En ligne], Hors-série $n^{\circ} 2$ | 2008, mis en ligne le 19 janvier 2009, consulté le 04 mars 2023. URL : http://journals.openedition.org/cem/9642 ; DOI : https:// doi.org/10.4000/cem.9642

Este documento fue generado automáticamente el 4 marzo 2023.

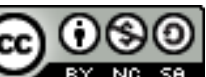

Creative Commons - Attribution - Pas d'Utilisation Commerciale - Partage dans les Mêmes Conditions 4.0 International - CC BY-NC-SA 4.0

https://creativecommons.org/licenses/by-nc-sa/4.0/ 


\title{
Representar, instituir, redimir : oralidad y escritura en los textos forales
}

\author{
Paola Miceli
}

1 A partir de mediados del siglo XI, con el triunfo de Alfonso VI como rey de León, la política de puesta por escrito de los ordenamientos jurídicos locales se transforma en una práctica extendida. El monarca es un importante motor de este proceso de otorgamiento de fueros, cartas pueblas y privilegios; pero no es el único. Por doquier vemos señores laicos y eclesiásticos que para mantener sus posiciones se ven obligados a conceder estos textos. Si bien existen unos pocos fueros previos que aparecen otorgados en época condal - los de Lara y Canales de la Sierra por Fernán González a mediados del siglo X y los de Salas de los Infantes, Melgar de Suso y Castrojeriz por García Fernández a fines del mismo siglo -, se trata de textos poco confiables por haberse transmitido por diplomas del siglo XII y por presentar anomalías diplomáticas y anacronismos institucionales que han motivado en algunos casos su consideración como apócrifos ${ }^{1}$. Ahora bien, más allá de la autenticidad o no de estos documentos, lo cierto es que es recién para la segunda mitad del XI cuando puede verse en todo su despliegue este fenómeno de otorgamiento de fueros a distintas comunidades, hecho que se consolida a lo largo de los siglos XII y XIII ${ }^{2}$. Nuestro trabajo quiere dar cuenta de este fenómeno de escritura y concesión de fueros en el Reino de León en los siglos XI y XII. No se tratará de un trabajo que despliegue las razones históricas de esta puesta por escrito, cuestión que los especialistas han trabajado en profundidad ${ }^{3}$, sino que, por el contrario, la exposición se orientará a indagar acerca del valor e implicancias históricas y metodológicas de este fenómeno de escrituración.

2 Preguntarse por este acontecimiento de puesta por escrito de los ordenamientos jurídicos locales implicó trabajar en una doble dimensión : por un lado, sobre el papel que los historiadores le hemos asignado a la puesta por escrito de la norma jurídica - a este aspecto remiten los dos primeros infinitivos del título : representar e instituir - ; por otro, significó trabajar en torno de los argumentos que los propios fueros utilizaban 
para explicar el otorgamiento de un texto escrito - esta perspectiva es la que hemos querido sintetizar con el verbo redimir.

Representar

3 Una larga tradición de historiadores que trabajaron sobre fueros ha señalado que el otorgamiento del mismo por parte de la autoridad real o de algún señor local no agregaba nada al ordenamiento jurídico previo en la medida en que se trataba de confirmar un derecho ya existente en el lugar. El rey, el señor o el monasterio en el momento de dar fuero ponían por escrito el derecho que se encontraba vigente en el lugar y que se había trasmitido de forma oral de generación en generación. Esta oralidad del derecho de la comunidad fue asociada en términos generales con la existencia en la región de un derecho consuetudinario en relación con el derecho germánico. En León la tesis germanista sostenía que después de la invasión musulmana del siglo VIII, con la caída en desuso de la ley visigoda, resurgió un derecho germánico que ya se encontraba latente bajo el dominio de la Lex Visigothorum y que siempre se había resistido a ella - lo cual, según los germanistas, se vislumbraba en la existencia de un doble ordenamiento, uno para la población goda y otro para la hispano-romana. En la impasse entre la ley visigoda y el derecho romano emergía la costumbre deudora de un derecho antiguo de raíz popular, el derecho germánico. Para un historiador clásico de esta corriente como Hinojosa, los fueros debían ser considerados entonces como la plasmación escrita de un derecho consuetudinario preexistente. Así, el texto escrito del fuero era interpretado como la cristalización de un orden jurídico consuetudinario que se encontraría latente.

4 Pero esta imagen de la escritura del fuero como concreción de una tradición oral no está presente solamente en los germanistas. En efecto, el tópico de la cristalización mediante la norma de la experiencia que nace de los hombres y de las cosas parece recorrer buena parte de los trabajos de los historiadores y juristas. Tomemos algunos ejemplos. En principio, dos clásicos, uno de la historia del derecho en Italia, Paolo Grossi, el otro de la historiografía hispánica, Galo Sánchez. Nos dice el primero :

He aquí cómo debemos observar al derecho medieval : como una gran experiencia jurídica que alimenta en su seno una infinidad de ordenamientos, donde el Derecho - antes de ser norma y mandato - es orden, orden de lo social, motor espontáneo, lo que nace de abajo, de una sociedad que se autotutela ante la litigiosidad de la incandescencia cotidiana ${ }^{4}$.

5 Esta es su opinión acerca del derecho en la edad media, un derecho que fluye y emana de las cosas, que está inscrito en las cosas. No existe distancia entre el hecho y el derecho, pues en esta versión romántica el hecho es en sí mismo derecho, el hecho por su fuerza intrínseca es derecho, fuerza que le permite « incidir de forma duradera sobre la experiencia ${ }^{5} »$. Hecho, derecho y experiencia se encuentran anudados, dado que, según Grossi, en el derecho medieval es imposible hablar de uno sin hablar del otro. El hecho con su capacidad de provocar efectos duraderos en la experiencia cotidiana del hombre se transforma en derecho.

6 La norma jurídica se encuentra latente en el mundo ; los doctos a través de la escritura se encargan de sacarla a la luz utilizando los recursos de su saber. Galo Sánchez al analizar la constitución de los derechos territoriales en la vieja Castilla pone de relieve cómo se constatan en dicho proceso dos estrategias diferentes pero complementarias de la práctica jurídica : en primer lugar, el redactor fija por escrito una norma latente en la «vida consuetudinaria »; en segundo lugar, la convierte en norma abstracta ${ }^{6}$. 
Escribir la norma no significa crearla sino hacerla pasar del plano de la experiencia rústica de la oralidad al de la sofisticación de la escritura.

Oralidad y escritura se presentan, entonces como dos momentos distintos de la norma pero consecutivos. La escritura plasma, representa unas experiencias jurídicas que se trasmitían de generación en generación en el estado de inocencia de la oralidad.

Instituir

Durante estos años un objetivo constante en la mayoría de mis trabajos ha sido realizar una revisión crítica de estos planteos que ven en el discurso jurídico un mero agente cristalizador de hechos y prácticas que se crean, transcurren, funcionan, en definitiva, que existen, en un registro diferente al del discurso jurídico, el registro de lo social, de lo económico, etc. Con esta intención es que me puse a trabajar sobre los textos forales desde una dimensión distinta a la que acabo de exponer. Si desde las interpretaciones tradicionales redactar un fuero era concebido como el acto de sacar a la luz un ordenamiento jurídico encarnado en las prácticas populares de una comunidad, que existía como tal en tanto conglomerado de hombres, entonces comencé a pensar la escritura del fuero como acto fundacional de la propia comunidad, aun cuando encontráramos hombres y mujeres asentados en el lugar antes del otorgamiento del texto jurídico.

9 Esta línea de trabajo intentaba dar cuenta de uno de los tantos mecanismos mediante el cual en torno de los siglos X y XI se produjo en el Occidente medieval la conformación de las comunidades de habitantes, fenómeno que la historiografía de los últimos años ha estudiado en profundidad señalando las múltiples operaciones que lo hicieron posible : el papel aglutinante de la parroquia o el cementerio, las prácticas señoriales de reorganización del espacio que llevaron a los campesinos a concentrase en torno a los castra, las prácticas específicas mediante las cuales los habitantes de un lugar se apropiaron de ese espacio, etc. ${ }^{7}$. Considerábamos en nuestra investigación ${ }^{8}$ que en el estudio de este proceso se había prestado poca atención a un dispositivo a nuestro entender clave : el papel del texto foral como discurso instituyente ${ }^{9}$ de la comunidad de habitantes a partir de la invención de una tradición ${ }^{10}$ jurídica común a todos los que moran en un lugar. Pensar el fuero como discurso que instituye, como la operación mediante la cual se ponen las condiciones para la existencia de la comunidad de habitantes, implicó un revisión del problema, habitualmente pensado en clave antropológica, del papel de la memoria y de la transmisión oral de la norma : desde esta nueva perspectiva la existencia o no de una norma de transmisión oral previa a la puesta por escrito del ordenamiento jurídico tenía poca importancia ya que lo que cobraba fuerza en la interpretación era la capacidad del texto foral de otorgar memoria. En los fueros breves de León que tomamos como referencia en este trabajo no se dice esto de manera explícita - ya veremos de qué manera se instituye memoria - pero sí queda expuesto sin giros retóricos en el Fuero de Béjar (s. XIII) :

Esta memoria otorgo demas a todos los pobladores, qua quier uenir quisiere poblar

Beiar... non responda por enemiztad, ni por debdo, ni por fiadora, ni por erentia, ni por ninguna cosa que fizo ante que Beiar se poblasse ${ }^{11}$.

10 En Béjar el dador del fuero instituye una memoria que requiere el olvido de ciertos hechos sucedidos antes de la concesión del fuero. En el caso de los fueros de León el escrito no borra lo anterior sino que instaura una tradición.

11 Esta idea de creación de una memoria común para todos los que habitan en un lugar se sostenía en mi investigación, mejor dicho se sostiene porque sigo trabajando en ello, en 
el uso en los Fueros de León de tres términos cuyos significados connotan la idea de una práctica que se realiza desde antiguo, me refiero a los conceptos de consuetudo, usus, mos. Hagamos un rápido recorrido por estas nociones.

A lo largo de los siglos XI y XII es cada vez más frecuente la utilización en los fueros del vocablo consuetudines para hacer referencia a la obligaciones que los pobladores de un lugar le deben al rey o al señor ya sea laico o eclesiástico - Alfonso VI a los pobladores de Sahagún : «Doy a vosotros hombres pobladores de San Facundo consuetudines y fueros con que vivais y sirvais a la Iglesia y al monasterio ya mencionados ${ }^{12}$. " Aun cuando en la mayoría de los casos se haga constar su remotísima o inmemorial observancia, las consuetudines "son concedidas por reyes o señores a un lugar de nueva población, a manera de privilegio, o bien... se crean por un pacto para dirimir un pleito ${ }^{13}{ }^{»}$. El término no se refiere a un derecho público sino al conjunto de imposiciones que los señores exigen a sus campesinos. Que se las denomine consuetudines indica que esas normas ya se aplican, o deberán usarse y aplicarse, pero no que hayan nacido de la repetición continuada de unos mismos actos. Estas imposiciones son, evidentemente, la huella en los documentos del avance señorial y de la imposición del poder de ban. Pero, ¿por qué se las denomina así ? En su estudio sobre este mismo fenómeno en el Mediodía francés, Poumarède plantea que el uso de los términos consuetudines o usus para referirse a las obligaciones feudales sería un intento de legitimar la violencia y la arbitrariedad de las imposiciones señoriales inscribiéndolas en una cadena de recuerdos que conformarán la memoria de esa comunidad. Denominar a las nuevas obligaciones consuetudines implicaba entonces instituirlas como parte de un recuerdo de la comunidad: si se trata de costumbres, entonces siempre debió realizarse así ${ }^{14}$. La operación discursiva busca borrar la novedad de la imposición bajo un nombre (consuetudines) que encierra la idea de hábito que se repite desde tiempos antiguos. En principio, estamos de acuerdo con el autor, pero la utilización del término consuetudines es algo más que la inclusión de un recuerdo nuevo en una memoria comunal preexistente a través de una estrategia de enmascaramiento. Si de lo que estamos hablando es de considerar la redacción de los textos forales como acto fundacional, entonces el uso del término consuetudines debería ser pensado como el testimonio de la capacidad del discurso jurídico de instituirse como fuerza creadora de la comunidad, en la medida en que establece hábitos y funda memoria. Denominar consuetudines a una imposición es, pues, un acto de fuerza que, operando en el terreno de la memoria, construye la identidad jurídica necesaria para la existencia de la comunidad.

El término usus posee un campo semántico más amplio : puede usarse como sinónimo de consuetudines, reforzando así la idea de una imposición señorial que debe cumplirse como si tuviera antigüedad, o puede emplearse como práctica habitual sin valor normativo. Pero existe en el caso de usus otra variante en su utilización. En el fuero de Sahagún, en la cláusula 30 se lee :

Y el abad y los monjes los defiendan y amen como a sus hombres. Y los montes, las cosas y las heredades del monasterio permanezcan en paz según sus usus et leges antiquas, por mano del abad y de los monjes ${ }^{15}$.

14 La utilización conjunta de los términos usus y leges antiquas reafirma la dimensión tradicional y obligatoria que una práctica tiene o debe tener. Según los especialistas, es muy factible que esta disposición sea una copia de los cuatro primeros preceptos del fuero de León, que a su vez parece ser un resumen de varias leyes del Liber Iudiciorum, especialmente aquéllas donde se afirmaba la potestad episcopal sobre las personas consagradas, iglesias, monasterios y propiedades de tal condición. Cuando el protocolo 
del fuero señala que la obligatoriedad de esa imposición se justifica porque de ese modo se practicó desde los visigodos, queda presentada así la operación mediante la cual se está instituyendo una tradición jurídica que da identidad a esa comunidad de habitantes. De esta forma, a partir de la redacción y concesión de este fuero, los hombres y mujeres que moran en el lugar adquieren una serie de obligaciones para con el monasterio que deben seguir realizando como norma, ya que el fuero ha establecido que se trata de una práctica recurrente desde la antigüedad. Nuevamente, una región, una tierra, adquiere a través del fuero un ordenamiento presente que crea hacia atrás un antecedente, esto es, los usos y las leyes de épocas visigodas; los hombres y mujeres instalados allí obtienen de este modo un pasado jurídico que queda instituido como memoria legal de los que habitan en ese territorio.

Mos es el último término a analizar. Se trata de un concepto profundamente marcado por la tradición romana. En efecto, el mos maiorum ejercía en Roma una gran influencia en las esferas del derecho, la religión, la disciplina militar, la educación de los hijos, el comportamiento público y privado, etc. Se trataba de un conglomerado de reglas no enunciadas sistemáticamente, inmanentes a las prácticas, que poseían un carácter modélico. Tanto Varrón en el siglo I a.C. como Ulpiano en el I d.C. hablan de dos requisitos necesarios para la constitución del mos: que se desarrolle con el consentimiento de una comunidad y que sea consolidado por el tiempo. Entre los jurisconsultos bajoimperiales se fortalece la idea de que mos es la norma en el sentido de lo que tácitamente ha acordado el pueblo romano - y que lo identifica como tal - y de lo que está arraigado por el uso ancestral.

Ahora bien, cuál es el uso que los textos forales hacen de este término ? En la cláusula número 4 del fuero dado a León y a sus alrededores por Alfonso V en el año 1017, leemos :

Mandamos hasta este momento que nadie ose robar algo de la iglesia, pero si ha sustraído algo del interior del cementerio por rapiña, salve el sacrilegio, y cualquier cosa que de allí haya arrebatado, (ordenamos) que lo devuelva como rapiña ; si en cambio injustamente ha sustraído una cosa fuera del cementerio de la iglesia, (ordenamos) que restituya y (pague) caloña a los administradores de su propia iglesia more terre ${ }^{16}$.

Lo que sorprende en este fuero es que mos se presenta como comportamiento asignado a la tierra y no a los individuos. Es ella, más allá de los que la habitan, la que posee dichos hábitos: sus moradores son meros instrumentos de la tierra que se comporta como estructura, como reservorio de un conjunto de reglas que los hombres deben respetar. Los hombres en tanto habitantes de ese territorio devienen practicantes de un orden jurídico que les precede. El texto del fuero instituye entonces a la tierra como la portadora de un ordenamiento jurídico particular. Instituida como reservorio de las normas todo ocurre como si la tierra fuera la institución que instrumentaliza a los hombres en tanto apéndices orgánicos de la naturaleza inorgánica. Acompañando y reforzando esta idea de instrumentalidad la palabra mos es usada en ablativo (more terre). El empleo del término en este caso gramatical se encuentra ya presente con mucha frecuencia en el mundo romano; se utilizaba la expresión more maiorum o su reverso maiorum more como sintagma fijo que expresaba claramente su carácter paradigmático. Ahora bien, si en el mundo romano se adjudicaba a los antepasados la capacidad de establecer las reglas a seguir, en cambio, en este fuero medieval se concede esta competencia a la tierra. Es por esto que el fuero no explicita la forma en que debe llevarse adelante esta práctica. Hay una cualidad atribuida a la tierra que no 
necesita ser legislada porque la tierra posee su propio ordenamiento, del cual los hombres son apéndices o instrumentos. Entiéndase bien, no es la tierra en sí misma la portadora de esos derechos, al modo que podría plantear una mirada metafísica ${ }^{17}$, sino el gesto del derecho foral el que instaura a la tierra como reservorio de las prácticas jurídicas antiguas. Al igual que la utilización de consuetudines y usus, el efecto producido por el empleo del sintagma more terre es el de instaurar en un determinado sitio, en una determinada tierra, un conjunto de prácticas como ancestrales. Lo nuevo bajo el ropaje de lo antiguo, la escritura como creadora de memoria jurídica.

Esta línea habilita la posibilidad de pensar una idea de memoria diferente a la de las miradas románticas sobre el tema. Aquí la memoria no es recuerdo previo que se trasmite de generación en generación de forma oral, sino lo instituido a partir de la escritura del fuero que inaugura a partir de ese momento una tradición. Así pensada, la escritura no opera como agente cristalizador de un hacer desplegado a partir de la oralidad sino como práctica que otorga sentidos nuevos.

Redimir

Como dijimos al inicio, la pregunta acerca de la puesta por escrito de los ordenamientos jurídicos locales nos enfrentó a tres formas distintas de abordaje del problema planteado. La primera estrategia que puntualizamos, la de la representación, concebía a la escritura del fuero como plasmación de una tradición jurídica que se venía trasmitiendo de forma oral. La segunda, que criticaba vivamente esta mirada, pensaba la puesta por escrito de la norma como acto instituyente de la tradición. Ahora bien, sería interesante a esta altura indagar qué valor le atribuyen a la escritura quienes otorgan estos documentos. Esta es la tercera estrategia de acercamiento al problema que nos queda por tratar : la del imaginario acerca de la escritura de quienes ponen por escrito la norma más allá del papel que los historiadores le asignemos a la misma.

Varios son los argumentos que justifican la puesta por escrito de la norma que encontramos en los protocolos o encabezados de algunos fueros. En primer lugar, aparece el topos clásico de la escritura como reaseguro contra el olvido :

Los hechos que no son trasladados a la página se escapan fácilmente de la mente humana. Conocido sea para todos los oyentes tanto presentes como futuros, que yo el conde Don Froila con mi esposa la condesa Doña Sancha hicimos carta a vosotros hombres habitantes de la villa llamada Cifuentes, tanto presentes como futuros, para que cada uno conozca el fuero que debe hacernos en la mencionada villa ${ }^{18}$; En el nombre de nuestro Señor Jesucristo, amén. Puesto que las cosas que los reyes y príncipes de la tierra disponen misericordiosamente son confiadas por escrito, no sea que por el paso de los tiempos caigan en el olvido, yo Berengaria (...) alabo, apruebo y confirmo a Dios y al monasterio de San Pedro de Eslonza estas libertades y consuetudinem... ${ }^{19}$.

21 La escritura es un conjuro contra el paso del tiempo. Las cosas dadas por los reyes y señores se hacen más recientes por medio de lo escrito « ea quae a regibus donatur scriptis recentiora habentu ${ }^{20}$ » ya que se revalidan por el testimonio de las letras. Si la vetustez de los tiempos hace que las cosas se olviden, la escritura las afirma y robustece.

La escritura se presenta también como el medio más idóneo para comunicar y fortalecer los actos de liberalidad, las donaciones, etc., de aquellos que detentan el poder : se señala con frecuencia que es parte de la tarea de gobernar « hacer posible el conocimiento de la norma mediante la escritura de modo que siempre esté manifiesta y por nadie sea ocultada ${ }^{21}$ ", tarea que compete a los reyes pero también a los príncipes y nobilísimos varones, los piadosísimos abades y monjes, e incluso a las mujeres ${ }^{22}$. Este 
acto de generosidad que es otorgar un ordenamiento jurídico escrito debe ser interpretado también a la luz de los conflictos que se traman en este período entre la nobleza y el rey, entre distintos señores feudales, etc. Para proteger estos buenos fueros donados ${ }^{23}$ de amenazas futuras se establecen penas a quienes intenten violarlos. Estas cláusulas penales contemplan casi siempre una amenaza de carácter religioso o espiritual de naturaleza muy diversa - maldición eterna, condenación en el infierno, exclusión de la comunidad religiosa, etc. También suelen incluir una serie de penas corporales - privación de la vista, la lepra de Giezi ${ }^{24}$, entre otras - de claras reminiscencias bíblicas y otras de carácter económico. El fuero de San Pedro de la Dueñas es un buen ejemplo :

si alguno, empero, cegado de avaricia, sea prior abadesa o persona de otra orden o dignidad que pretendiera infringir esta carta hecha y roborada por nosotros (...), primeramente sea excomulgado y maldito, y el abismo de la tierra le trague vivo como a Datán y Abirón, y sufra eternas penas en el castigo sempiterno con Judas Iscariote que traicionó al Señor y además pague cien sueldos... ${ }^{25}$.

Muchas de estas fórmulas conminatorias que encontramos en buena parte de los diplomas legionenses suelen estar ya presentes, en algunos casos con variantes, en formularios redactados en época temprana con el fin de proporcionar modelos que debían seguir los notarios encargados de redactar cualquier tipo de documento, tal es el caso de las llamadas Formulae Wisigothicae ${ }^{26}$; de hecho algunos de los elementos de las fórmulas conminatorias de los fueros de León ya están presentes en ellas ${ }^{27}$. Pero la existencia de estos anatemas, como sabemos, no es una peculiaridad del mundo hispánico, por el contrario se trata de una práctica muy común hasta el siglo XII en la sociedad feudal en su conjunto ${ }^{28}$. La inclusión de estas sanciones evoca de alguna manera el carácter sacrosanto que tenían las leyes en Roma ${ }^{29}$. Volveremos sobre estos anatemas un poco más adelante.

La importancia de disponer de un documento escrito se vuelve crucial en estos siglos para los poderes locales, y también para las comunidades : es necesario contar con el testimonio escrito del fuero recibido o probar su concesión por otros medios ${ }^{30}$ para proteger los privilegios o buenos fueros obtenidos. Los reyes en algunas ocasiones confirman los buenos fueros que los vecinos juran haber recibido de una antepasado remoto, generalmente se trata de un rey famoso, pero en otras no es tan crédulo. Existen casos de vecinos que no logran ver confirmados los buenos fueros a los que aspiraban, pese a presentar carta escrita de los mismos, pues se encontró la carta « enmendada e entreliniada en lugares sospechos et de dos manos porque semeja que non debíen valer ${ }^{31} »$. Los dominados conocen el poder de la escritura y por eso exigen la puesta por escrito de sus privilegios, pero también saben que el documentum, el escrito, no tiene valor sin una auctoritas que lo legitime. De allí el permanente reclamo de confirmación, sea por los sucesores de aquel que lo concedió, sea a través de sentencias judiciales, etc. Fuerza y debilidad del escrito, como ya ha señalado Clanchy ${ }^{32}$, el escrito no tenía ningún valor por sí solo ; la comprobación por el peso que tenían los testimonios orales era lo que lo hacía verdadero y no al revés. No debemos olvidar que en la mayoría de los casos los textos escritos estaban pensados para circular en un mundo donde la oralidad seguía siendo aún la forma de comunicación más importante. De allí la presencia de expresiones tales como: "hanc kartam quam fieri iusimus et legendo audiuimos roboramus ${ }^{33}$ ". Al final de cada fuero hallamos la detallada lista de aquellos testigos que estuvieron presentes y que confirman el acto de otorgamiento del documento. Aparecen también otros elementos corroborativos 
mediante los cuales se certifica que el documentum ha sido elaborado siguiendo los formalismos requeridos: frases que demuestran que el dador del fuero efectivamente ha dado la orden de que se ponga por escrito - mandé dar esta mi carta o hanc chartam fieri isuss - ; la presencia del sello - confirmamos et signum in ea scribi jussimus, signo - ; el establecimiento de la robra.

Por último la escritura del fuero se presenta como acto redentor. Tanto en los protocolos iniciales como en los finales de los Fueros de León encontramos distintas formas de expresar esta idea siendo el sintagma más frecuente ob remedium anime mee et parentum. En el fuero a San Pedro de las Dueñas leemos « hanc autem seriem scripture facimus uobis, in primis propter amores dei omnipotentis et pro remissione omnium peccatorum nostrorum ${ }^{34} »$ - esta escritura os damos a vosotros, primero por amor de Dios omnipotente y por remisión de todos nuestros pecados - ; en el de Villarratel :

En el nombre de Dios, amén. Yo condesa Sancha Ponce en unión de mis hijos...

Primeramente por amor de Dios y en remedio de nuestra almas y de nuestros parientes hacemos carta de buen fuero ${ }^{35}$.

Conceder un escrito o confirmarlo tiene en el imaginario de estos siglos la facultad no sólo de evitar el olvido o engrandecer la obra de quienes gobiernan, sino también la de redimir y por lo tanto salvar el alma de quien lo concede y las de sus parientes. Es este valor redentor de la escritura en los textos forales el que creo que hay que indagar en profundidad. Probablemente esta imagen de la escritura esté asociada al valor que la ley poseía en estos siglos de la Edad Media como maestra de las cosas de Dios. Ya en el "Liber Iudiciorum (1.2.2) podemos ver a la lex como « aemula divinitatis, antistes religionis, fons disciplinarum, artifex iuris, bonos mores (...) magistra vital ${ }^{36}{ } »$. Esta idea es retomada en el Fuero Juzgo (1.2.2) de la siguiente manera :

La ley es por demostrar las cosas de Dios, é que demuestra bien bevir, y es fuente de disciplina, é que muestra el derecho, é que faze, é que ordena las buenas costumbres... é ama iustitia, y es maestra de virtudes ${ }^{37}$.

Si la ley enseña las cosas que son de Dios entonces el acto legislativo es misericordioso porque guía al pueblo hacia una vida llena de virtudes y por esta misma razón engrandece y salva el alma de quien legisla. En los fueros que estudiamos se ha trazado una fuerte relación entre el acto legislativo y su puesta por escrito, de allí que la escritura adquiera también ese valor redentor presente en la tarea de legislar. En esta línea sería sugestivo releer los anatemas presentes en los protocolos finales de los fueros. No hay duda, como ya indicamos, de que estos anatemas son la marca textual de las fuerzas en conflicto en el momento de otorgamiento del fuero, pero podría ser interesante poner en relación estas maldiciones con el papel otorgado a la escritura : quien viola la carta atenta contra un medio de salvación por eso merece ser anatemizado.

Sortilegio contra el olvido, reaseguro contra amenazas futuras, redención de las almas es el lugar que la escritura de la norma tiene en el imaginario de quienes otorgan y reciben el fuero.

Conclusión

29 En el marco de este encuentro cuyo objetivo central es discutir acerca de los modos de abordaje de las fuentes y de los conceptos apropiados para el estudio de la Edad media, este trabajo ha pretendido plantear una reflexión acerca de las distintas maneras posibles de acercamiento al problema de la escritura de la norma y su «real». Representar, instituir, redimir, estos tres infinitivos que organizaron la exposición 
tuvieron por intención significar tres estrategias de abordaje del problema planteado, la relación entre esta peculiar forma de norma escrita que es el fuero y la tradición oral. La primera estrategia considerada como un abordaje naïve intentó ser superada por una mirada sobre el fuero que privilegiara su papel fundador de la comunidad al otorgar a los pobladores del lugar una memoria jurídica común, así la norma escrita dejó de ser «iluminación desde arriba de lo que se arrastra por la tierra " para transformarse en la práctica que instituye a la tierra como instancia portadora de la tradición y la normatividad.

Ahora bien, esta mirada instituyente encarna un riesgo : perder de vista cuál es el imaginario acerca de la escritura de los propios actores involucrados en la concesión de un fuero. De allí que hayamos intentado al final de la exposición un acercamiento al problema mucho más pegado a los propios argumentos de los textos forales teniendo obviamente siempre presente que la voz de quienes dictaron estos documentos es desgraciadamente o felizmente (para lo medievalistas) irrecuperable.

\section{NOTAS}

1. Ver A. M. BARRERO GARCíA, « Los derechos de Frontera ", in Las sociedades de Frontera en la España medieval. II Seminario de Historia Medieval, Zaragoza, 1993, p. 69-80 ; A. M. BARRERO GARCíA, « El proceso de formación de los Fueros Municipales », in J. ALVARADO PLANAS, coord., Espacios y Fueros en Castilla-La Mancha (Siglos XI-XIV). Una perspectiva metodológica, Madrid, 1995, p. 61-88.

2. Es importante tener en cuenta el papel fundamental que ocupa la recuperación del derecho romano en la ampliación de este fenómeno de escrituración. Tradicionalmente se consideraba que la redacción de las costumbres a partir de los siglos XI y XII era una forma de resistir el avance de un derecho nuevo, extranjero y culto como el romano. Para García Gallo, por ejemplo, « en todas partes, el pueblo se resistió a la recepción del derecho común y al empeño de los juristas de aplicarlo en toda ocasión » en « Aportación al estudio de los fueros », AHDE, 26 (1956), p. 387-446, p. 408. Los estudios de A. Gouron en la región del Mediodía francés han puesto en entredicho esta idea : la difusión del derecho romano y la redacción de costumbres lejos de oponerse fueron dos aspectos de un mismo fenómeno. Dicho fenómeno consistió en la reificación de la regla jurídica como instrumento privilegiado de mediación en las relaciones sociales. Ver A. GOURON, "Sur les origines de l'expression "droit coutumier" ", Glossae. Revista de Historia del Derecho Europeo, 1 (1988), p. 179-188, y " Aurore de la coutume », Recueil de mémoires et travaux. Société d'histoire de droit et des institutions des anciens pays de droit écrit, 14 (1988), p. 181-187, ambos en Droit et coutume en France aux XII et XIII ${ }^{e}$ siècles, Norfolk, 1993.

3. Para un análisis del marco socio-político en el cual se otorgan estos documentos ver J. ALVARADO PLANAS, coord., Espacios y Fueros en Castilla-La Mancha (Siglos XI-XIV). Una perspectiva metodológica, Madrid, 1995 ; AA.VV, Las sociedades de Frontera en la España medieval, Zaragoza, 1993 ; A. M. BARRERO GARCíA, « La política foral de Alfonso VI », in 
Estudios sobre Alfonso VI y la reconquista de Toledo. Actas del II Congreso internacional de estudios mozárabes, Toledo, 1987, p. 115-156 ; AA.VV, el Reino de León en la Alta Edad Media. II Ordenamiento jurídico del reino, León, 1992 ; A. GARCíA GALLO, « Aportación al estudio de los fueros », AHDE, 26 (1956), p. 387-446; R. GIBERT, « El derecho municipal de León y Castilla », AHDE, 31 (1961), p. 695-753 ; A. GARCíA GALLO, « El fuero de León », AHDE, 39 (1969), p. 5-171; J. A. SARDINA PÁRAMO, El concepto de fuero. Un análisis filosófico de la experiencia jurídica, Santiago de Compostela, 1979.

4. P. GROSSI, El orden jurídico medieval, Madrid, 1996, p. 54.

5. P. GROSSI, El orden..., ibid., p. 75.

6. G. SÁNCHEZ, « Para la historia de la redacción del antiguo derecho territorial castellano », AHDE, 6 (1929), p. 260-328.

7. En realidad, estos procesos no deberían plantearse como mutuamente excluyentes sino como combinaciones de un mismo desarrollo, tal como lo plantea R. Fossier ( $L a$ infancia de Europa, Siglos X-XII. Aspectos económicos y sociales, Barcelona, 1984, 2 vol.) a partir del concepto de encellulement, que designaría el proceso de creación de las comunidades de habitantes en el marco de un encuadramiento a la vez parroquial y señorial.

8. Hago referencia a un artículo en prensa « Según la tradición de la tierra. Comunidad rural y práctica jurídica en los fueros medievales ", in J. GALLEGO y P. MICELI, Habitar, producir, pensar el espacio rural. De la antigüedad al mundo moderno, Buenos Aires (a publicarse en el 2007).

9. La noción de institución, que se utilizaba con el fin de reemplazar la noción tradicional de representación, entiende la relación entre lo real exterior al discurso y la formalización del texto foral de forma radicalmente diferente a la idea de representación. Esta última supone, en primer lugar, un « algo » exterior al discurso que debe ser vuelto a presentar por este último, y, en segundo lugar, una relación especular entre el discurso que nomina y lo nominado que queda re-presentado en la formalización. Instituir implica, por el contrario, un acto de fundación. La relación no se establece entonces en términos de adecuación entre un mundo dado y preexistente y un discurso que a posteriori habla de él, sino en términos de creación.

10. Cf. J. GALLEGO, La democracia en tiempos de tragedia. Asamblea ateniense y subjetividad política, Buenos Aires, 2003, sobre todo el capítulo VII : « Nacimiento de la democracia, invención de la historia ", p. 241-271.

11. J. G. CUADRADO, Fuero de Bejar, Salamanca, 1975. El fragmento corresponde a la cláusula $\mathrm{n}^{\circ} 4$ del fuero.

12. J. RODRíGUEZ, Los fueros del reino de León, Madrid, 1981, t. 2, « Istas consuetudines et foros per voluntatem Abbatis et collegio fratrum dedi ego Adefonsus Imperatur hominibus Sancti Facundi per quos serviant ei sicut Dominus submissione et humilitate plena », p. 39. La traducción de los fragmentos documentales citados a lo largo de este artículo se basa en la versión de J. Rodríguez, puntualmente reelaborada cuando la interpretación permite inducir otros sentidos. En algunos casos se han mantenido ciertos términos en latín debido a que constituyen el centro de nuestra interpretación.

13. A. garcía Gallo, Manual de historia del derecho español, Madrid, 1977, t. 1, p. 186. 14. Cabe plantear aquí la cuestión del uso social del lenguaje y la lucha por la apropiación de ciertos términos, hecho que Scott ha señalado como un aspecto fundamental de la lucha entre campesinos y señores ; J. C. ScотT, Weapons of the weak. Everyday forms of peasant resistance, New Haven, 1985. 
15. J. RODRÍGUEZ, Los fueros..., op. cit., p. 39 : «Et illi defendant eos et ament ut suos homines. Et sedeant montes, et res, et hereditates monasterii per suos usus et leges antiquas in pace per manum Abbatis et monachorum. "

16. J. RODRÍGUEZ, Los fueros..., ibid., p. 17 : « Mandauimos adhuc ut nullus audeat aliquid rapere ab ecclesia ; uerum si aliquid infra cimiterium per rapinam sumpserit, sacrilegium soluat, et quicquid inde abstulerit, ut rapinam reddat; si autem extra cimiterium iniuste abstulerit rem ecclesie, reddat eam et calumpniam cultoribus ipsius ecclesie more terre. " 17. Concepción que está presente de manera clara en P. Grossi, (El orden..., op. cit., p. 90-92), en especial, en el apartado « Hechos normativos fundamentales : tierra, sangre, duración ».

18. J. Rodríguez (Los fueros..., op. cit., p. 167), Fuero de Cifuentes de Rueda, dado por el conde Froila y su mujer Sancha en 1198 : «Facta que pagine non traduntur facile ab humanis mentibus elabuntur. Notum sit quomodo omnibus audientibus tam presentis quam futuris quod ego comes domus Froila una cum uxore mea comitissa domna Sancia uobis hominibus habitantibus in uilla que uocitatur cent fontes, tam presentibus quam futuris, facimus kartam in perpetuum ut sciat unusquisque quem forum debitis in predicta uilla nobis facere. "

19. J. RODRÍGUEZ, Los fueros..., ibid. : «In nomine nostri Ihesu Christi, ame. Quoniam ea que a regibus et principibus terrarum misericorditer fiunt scripto commendanda sunt, ne spatio temporum elapso obliuioni tradantur. Idcirco ego Berengaria (...) laudo, aprobó et confirmo Deo et monasterio Sancti Petri de Asluenza illam libertatem et consuetudinem. » Ver también (J. RODRíGUEZ, Los fueros..., ibid., p. 73), Fuero dado a los burgueses de Sahagún por Alfonso VII y el abad Domingo en 1152 : « Sicut in ovni contratu condiciones valere imperiales testatur autoriítas, sic etiam iustitiae ratio exigit ut quae a Regibus, sive ab Imperatoribus fiunt scripto firmentur, ne temporum diuturnitate oblibioni tradantur...»

20. J. RODRíGUEZ, Los fueros..., ibid., Privilegio otorgado por Alfonso VII a Cacauelos, 1130, p. 57.

21. J. RODRÍGUEZ, Los fueros..., ibid. (p. 159), Carta de encomendación de los hombres de behetría de Villanueva, Arantigua y Valle al monasterio (1198), « Magno opere quidem adiciendum est et sciatis norma et scriptura conclusa, ut semper loquatour et de nullo omnino numquam verecundetur... »

22. J. RODRíGUEZ, Los fueros..., ibid., Fuero de Quintanilla de Páramo, dado por la abadesa de Grandefes en 1173, p. 121.

23. Reciben este nombre aquellos fueros otorgados tanto por el rey como por los señores que tienen por objetivo eximir a una comunidad o un grupo de personas de determinadas prestaciones que en muchos casos son calificadas como malos usos (prestaciones abusivas).

24. Giezi, el personaje bíblico condenado a padecer lepra por haber cobrado por un milagro realizado por el profeta, es una presencia habitual en las fórmulas conminatorias de los documentos medievales. Suele ser ejemplo moral de castigo a avaros y codiciosos y en muchas oportunidades aparece citado junto a otros personajes funestos en la tradición exegética medieval como Judas, Caín, Datán y Abirón, etc. La referencia a Giezi se encuentra incluso en Novela 8 (Iusiurandum) : «Si vero non haec omnia servavero, recipiam hic et in futuro saeculo in terribili iudicio magni dei domini et salvatoris nostri Iesu Christi et habeam partem cum Iuda et lepram Giezi et tremorem Cain, insuper et poenis, quae lege eorum pietatis continentur ero subiectus ", Corpus Iuris Civilis, Berlín, 1904. Cf. A. MORIN, «El campo semántico de la lepra en Siete Partidas de Alfonso 
el Sabio », Temas Medievales, 12/1 (2004), p. 165-175 y R. MANCHóN GÓMEZ, « Tradición cristiana latina y diplomas medievales : las fórmulas conminatorias en los documentos del reino de León (s. VIII-1230) », Analecta Malacitana, 6 (2000).

25. J. RODRÍGUEZ, Los fueros..., op. cit., p. 53 : « Si quis tamen cupiditate excecatus, prior uidelicet uel abatías seu quilibet cuiuscumque ordinis aut dignitatis sit qui hanc kartam anobis factam et roboratam infrigere presumpserit et manneria in uilla sancti petri accipere uoluerit, in primis sit excomunicatus et maledictus et hiatos terre uiuus absorbeatur sicut datam et habiron et luat eternas penas sempiterna dampnatione cum iuda scariote domini traditore el insuper cogatur persoluere c. solidos de agerto... » Ver también Fuero dado por Alfonso VI a los clérigos de la ciudad de Astorga (p. 44) : «Quod si quisquam vel cujuspiam hanc nostram devotionem quod nos disposuimus, tam pro animae meae, quam etiam pro animae parentum meorum... sit anatema in conspectu Dei Patris Omnipotentes et Filii et Spiritus Sancti. Sit etiam in conspectu Angelorum ejes et Martyrumanathema maranata, id est, duplici confussione damnatus, ut de hoc saeculo sicut Datam et Abiron vivus térrea obsorbeatur... »

26. Cf. R. MANCHÓN GÓMEZ, « Tradición cristiana... », op. cit. ; J. BASTARDAS, « El latín de la Península Ibérica. 4. El latín medieval », in Enciclopedia. Lingüística Hispánica [ELH], t. 1, Madrid, 1960, p. 251-290, en concreto p. 270-271. Véase M. PÉREZ GONZÁLEZ, « Sobre el formulismo en la diplomática medieval », Iacobus 7-8, Valladolid, 1999, p. 117-139. 27. Como por ejemplo la referencia conjunta a Datán y Abirón los personajes bíblicos que se rebelaron contra Moisés y fueron tragados vivos por la tierra.

28. Ver L. K LITTLE, « La morphologie des malédictions monastiques », Annales ESC, 1979, p. 43-59 y M. ZIMMERMANN, «Protocoles et préambules dans les documents catalans du $\mathrm{X}^{\mathrm{e}}$ au XII ${ }^{\mathrm{e}}$ : évolution diplomatique et signification spirituelle », Mélanges de la Casa de Velásquez, 10 (1974), p. 41-73.

29. En el caso romano las leyes eran « santas » en tanto estaban marcadas por un interdicto de violación. Un tratado es sacrosantum « no porque es instituido por un juramento sino porque gracias a la interposición de un juramento, se instituye que, si alguien lo viola, expiará con su muerte. La sanción de la sacralidad, es decir, el abandonarse a la venganza divina y la garantía que esta confiere, es esto lo que produce en su origen el acto de sancire », Y. THOMAS, " De la "sanción" y la "santidad" de la leyes en Roma ", in Y. THомAs, Los artificios de las Instituciones, Buenos Aires, 1999, p. 208-209. 30. Como lo demuestra el fuero de Barbastro de 1115 en donde tres bonos barones que dicen haber visto el privilegio que el rey Pedro le hizo a los hombres del lugar deben probarlo frente al rey Alfonso. Cf. T. MUÑOZ Y ROMERO, Colección de fueros municipales y cartas pueblas de Castilla, León, Corona de Aragón y Navarra, t. 1, Madrid, 1847, p. 453-479. 31. J. GONZÁlEZ, Reinado y diplomas de Fernando III, t. 3 (Diplomas, 1233-1253), p. 398.

32. M. T. CLANCHY, From Memory to Written Record, England 1066-1307, Londres, 1979. 33. J. Rodríguez (Los fueros..., op. cit., p. 53), fuero dado a sus vasallos de San Pedro de la Dueñas por la abadesa Teresa en diciembre de 1124.

34. J. Rodríguez (Los fueros..., ibid., p. 53), fuero concedido a San Pedro de las Dueñas por la abadesa Teresa en 1124 .

35. J. Rodríguez (Los fueros..., ibid.), fueros dados a Villarratel por la Condesa Sancha Ponce en 1169 : «In primis pro amore Dei et pro remedio animarum nostrarum et nostrorum parentum facimus kartulam de bono foro » (p. 109). Ver también Carta puebla de Mansilla : " hanc autem donationem facio semper ualituram uobis populatoribus de Mansella et toti uestre generacioni ob remedium anime meae et parentum meorum... » (p. 131) ; Fuero dado por Fernando II a Lagos Babia en 1186 : « Eapropter ego rex domnus 
Fernandus una cum filio meo rege domno Afefonso, ob remedium anime mee et parentum... » (p. 137).

36. K. ZEUMER, Leges Visigothorum, in MGH, Legum Sectio I, t. I, 1902 citado por F. PACHECO, « Ley, costumbre y Uso en la experiencia jurídica peninsular bajomedieval y moderna », in El dret comú i Catalunya : actes del IV Simposi Internacional : homenatge al professor Josep M. Gay Escoda, Barcelona, 27-28 de mayo de 1994, Barcelona, 1995, p. 75-163, p. 77.

37. Fuero juzgo en latín y castellano, cotejado con los más antiguos y preciosos códices por la Real Academia Española, Madrid, 1815.

ÍNDICE

Mots-clés: écrit, oralité, fueros

\section{AUTOR}

PAOLA MICELI

Universidad Nacional de General Sarmiento/Universidad Nacional del Centro 